\title{
A CIÊNCIA A SERVIÇO DA SUSTENTABILIDADE AMBIENTAL - AS UNIDADES FITOAMBIENTAIS COMO ALTERNATIVA AOS IMPASSES DO NOVO CÓDIGO FLORESTAL
}

\author{
Franklin Galvão \\ Eng. Florestal, Dr., Prof. de Ecologia Florestal, Depto. de Ciências Florestais, UFPR, Curitiba, PR - fgalvao@ufpr.br
}

Cátia Augustin

Eng. Florestal, Jornalista, Mestranda em Engenharia Florestal, Conservação da Natureza, UFPR, Curitiba, PR - catiaraugustin@ gmail.com

Se o que prega a Constituição brasileira fosse compreendido de fato, o novo código florestal não teria sido aprovado na Câmara dos Deputados. Pelo menos, não integralmente. Porque não basta conhecer a lei, é preciso conhecer o objeto da lei. $O$ que falta a quem legisla sobre a natureza é conhecer a natureza.

O que os políticos, e os técnicos que os assessoram, consideram necessário para garantir um "meio ambiente ecologicamente equilibrado", "preservar e restaurar os processos ecológicos essenciais", "preservar a diversidade e a integridade do patrimônio genético do país" e "proteger a fauna e a flora, vedadas, na forma da lei, as práticas que coloquem em risco sua função ecológica" (Constituição federal, capítulo VI, art. 225, § $1^{\circ}$, I, II e VII) é um mistério impenetrável.

Durante as negociações para a aprovação do texto do novo código, reserva legal e áreas de preservação permanente (APPs) foram, por meses, manchetes na mídia. Mas, mesmo agora, depois de matéria votada, políticos, povo e jornalistas, desconhecendo, muitos deles involuntariamente, como a natureza funciona, não entenderam o porquê da polêmica. O debate acirrou-se em torno do tamanho das áreas, recuperação, anistia... Entre o que se deixou passar, no entanto, estão algumas das proposições mais equivocadas do novo texto.

De forma surpreendente - para tentar manter alguma educação -, alterou-se parte do art. $2^{\circ}$ do código antigo (lei n ${ }^{\circ} 4.771$, de 15 de setembro de 1965), que define as APPs nas margens dos rios. Passou de:

\footnotetext{
Consideram-se de preservação permanente, pelo só efeito desta Lei, as florestas e demais formas de vegetação natural situadas:

a) ao longo dos rios ou de qualquer curso d'água desde o seu nível mais alto em faixa marginal cuja largura mínima (...);
}

para, no Projeto de lei n ${ }^{\circ} 1.876-C$ de 1999 - o código recém aprovado pela Câmara dos Deputados:

$$
\begin{aligned}
& \text { Art. } 4^{\circ} \text { Considera-se Área de Preservação Permanente, em zonas rurais ou urbanas, pelo só efeito } \\
& \text { desta Lei: } \\
& \text { I - as faixas marginais de qualquer curso d'água natural, desde a borda da calha do leito } \\
& \text { regular, em largura mínima (...). }
\end{aligned}
$$

Inaugurando-se, assim, a vazão de água por decreto, ou melhor, por lei federal.

$\mathrm{O}$ código anterior prevê que as faixas marginais sejam consideradas a partir do nível mais alto do rio, porque o natural para o rio é ocupar o espaço necessário para cumprir sua função maior que é a de drenar uma área. Quando há um volume muito grande a ser escoado, o rio ocupa um leito maior; quando há pouca água, o fluxo diminui e o rio torna-se mais raso e estreito.

Estabelecendo-se a APP a partir da "calha do leito regular" deixa-se de se considerar as planícies de inundação como parte integrante dos rios, como regiões particularmente frágeis e ambientalmente fundamentais para uma série de processos naturais, entre eles a óbvia condução das águas em períodos de cheias, e passa-se a obrigar os rios a andarem na linha. O que pode ser, convenhamos, particularmente útil em áreas urbanas (contempladas na lei). Um rio obediente jamais invadiria, por exemplo, as marginais Tietê e Pinheiros, em São Paulo, onde o péssimo hábito das cheias atrapalha tanto o trânsito. Resta saber quem vai pagar o preço desta decisão. É preciso, ainda, definir o que será considerado "leito regular" no nordeste, onde há tantos rios intermitentes, e quem vai determinar o que é "regular" e o que não é.

Também há, no código antigo, a possibilidade de se compensar a área de reserva legal. Quem tem dinheiro e nenhum interesse em preservar terras para a reserva legal dentro da propriedade, pode, pelo Art. 44, inciso III: 
Compensar a reserva legal por outra área equivalente em importância ecológica e extensão, desde que pertença ao mesmo ecossistema e esteja localizada na mesma microbacia, conforme critérios estabelecidos em regulamento. (Incluído pela Medida Provisória nº 2.166-67, de 2001)

Considerando que:

$\S 4^{\circ} \mathrm{Na}$ impossibilidade de compensação da reserva legal dentro da mesma microbacia hidrográfica, deve o órgão ambiental estadual competente aplicar o critério de maior proximidade possível entre a propriedade desprovida de reserva legal e a área escolhida para compensação, desde que na mesma bacia hidrográfica e no mesmo Estado, atendido, quando houver, o respectivo Plano de Bacia Hidrográfica, e respeitadas as demais condicionantes estabelecidas no inciso III. (Incluído pela Medida Provisória $n^{\circ} 2.166-67$, de 2001)

Mas agora, no código novo, desaparecem do texto a microbacia, a bacia hidrográfica e até o estado, desde que sejam mantidos o bioma e a extensão da área, art. 38:

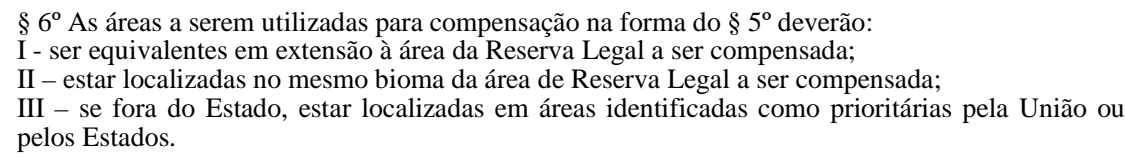

Autorizando-se a compensação de áreas desmatadas no Rio Grande do Sul, em Sergipe, Alagoas... Ou de florestas destruídas em São Paulo, no Maranhão. E estes estados não estão relacionados aqui por qualquer preconceito geopolítico, mas para revelar o quão distante uma reserva legal pode vir a estar de sua origem, do local onde a exploração de terras a torna necessária. É preciso perguntar aos cidadãos brasileiros se eles querem abrir mão de seu direito às reservas legais em seus estados.

Não é preciso mais que um conhecimento primário em ecologia para saber que, mais uma vez, a natureza será refém do poder econômico. Se dinheiro houver, teremos estados onde só existirão florestas nas APPs e nas unidades de conservação, e outros, onde as terras custarem menos, mais preservados. O que é ambientalmente desequilibrado e francamente inconstitucional por desrespeitar tudo o que prevê o art. 225.

Segundo o Vocabulário básico de recursos naturais e meio ambiente, do IBGE, bioma é o conjunto de vida (vegetal e animal) definido pelo agrupamento de tipos de vegetação contíguos e identificáveis em escala regional, com condições geoclimáticas similares e história compartilhada de mudanças, resultando em uma diversidade biológica própria.

O problema não é existir generalizações deste porte, é considerar esta [bioma] a unidade pertinente para o estabelecimento da reserva legal.

Felizmente, entre um código ideal que ninguém cumpre e os problemas do novo, há alternativas.

Antes que se retome a argumentação de que temos mais floresta preservada que qualquer país do mundo - o que também não é verdade -, é preciso entender que o Brasil não é só a Amazônia, apesar de ser nossa floresta mais carismática. E apenas na Amazônia Legal, por suas dimensões extraordinárias, os índices de preservação são expressivos. Há, no restante do país, regiões onde as formações originais foram devastadas, onde não é possível ceder mais simplesmente por já se ter ultrapassado há muito a fase crítica. Nestas regiões, é preciso recompor e manter áreas naturais mínimas. E é preciso que esta restauração se dê localmente, não no vasto espaço de um bioma.

\section{UNIDADES FITOAMBIENTAIS DO PARANÁ - UM ESTUDO DE CASO}

No Paraná, das feições naturais, muito pouco ficou intacto. O que escapou dos cascos das mulas tropeiras, da mineração e da exploração madeireira, sucumbiu ao pisoteio do gado e à agricultura. Hoje, a imaginação é o principal item na bagagem de quem busca, nestas paisagens profundamente alteradas, a diversidade e a força das formações vegetais originais.

A tibieza da aplicação da legislação não tem ajudado em nada. As APPs são negligenciadas e a reserva legal no estado disputa palmo a palmo com pastagens e culturas o chão da propriedade rural. Nas fazendas onde o relevo é fortemente ondulado, a mecanização é precária e a exploração econômica é inviável, não há tantos problemas, a reserva existente até supera os $20 \%$ exigidos para o Sul do país. Já nas áreas planas, onde o solo é profundo e fértil, a destinação de espaços para conservação é pífia.

Para evitar que a perda de biodiversidade se agravasse ainda mais, um grupo de pesquisadores da Universidade Federal do Paraná - UFPR, da Empresa Brasileira de Pesquisas Agropecuária - EMBRAPA e do Instituto Ambiental do Paraná - IAP*, há alguns anos, desenvolveu o conceito de Unidades Fitoambientais, as UFAs.

Uma UFA é um módulo de gestão ambiental, uma unidade ecológica onde há correspondência fisiográfica, geológica, de bacia hidrográfica, altitude e formação vegetal original, mesmo que desta última tenha restado apenas uma legenda em um mapa. 
As áreas, contínuas ou não, que mantêm uma razoável homogeneidade em relação a estes critérios são consideradas integrantes da mesma unidade. O território paranaense gerou 171 destas combinações, 171 UFAs.

As UFAs foram instituídas pela resolução 20/2008 da SEMA - Secretaria Estadual do Meio Ambiente - "como instrumento de política pública ambiental, em especial para análise de recuperação da cobertura vegetal e de supressão de vegetação nativa em estágio inicial no estado do Paraná".

A ferramenta foi criada para analisar os pedidos de supressão de vegetação nativa em estágio inicial - que, no momento, ainda tem respaldo legal (Lei do Bioma Mata Atlântica - $\mathrm{n}^{\circ} 11.428$, de 22 de dezembro de 2006). Tanto a supressão quanto a recuperação da cobertura vegetal passam a ser feitas levando-se em consideração a área preservada existente dentro de uma unidade e não apenas nas propriedades. Um software permite o enquadramento imediato de uma propriedade e/ou uma área a partir de suas coordenadas geográficas.

Uma unidade fitoambiental é uma compartimentação mais apropriada do que o que tem sido feito até agora, porque a vida faz combinações sutis para garantir sua viabilidade e continuidade. Uma mesma espécie apresenta variações caso tenha se adaptado para crescer no solo arenoso e no calor intenso do arenito Caiuá, no noroeste do estado, ou cresça um pouco mais ao sul, no solo argiloso, profundo e fértil de Foz do Iguaçu. Ainda que estas regiõ̃es estejam na mesma formação florestal - Floresta Estacional Semidecidual - e no mesmo bioma - Mata Atlântica. É simplista e incorreto considerar tudo a mesma coisa.

Pensar que é possível coletar sementes, produzir mudas e povoar o estado com plantas aparentadas (prática corrente), então, é ainda mais nocivo para a natureza do que deixá-la curar as feridas por conta própria. A única maneira de combater a erosão genética causada pelo intenso desmatamento é manter e recuperar espécies adaptadas segundo critérios mínimos de homogeneidade ecológica.

Assim, o alcance deste método [UFA] pode ser bem maior. O processo de análise diferenciada para a determinação de corte serve também como indicação de reconstituição da cobertura vegetal original do estado, evidencia fragilidades e potencialidades ambientais, proporciona aos técnicos entendimento da lógica das funções ambientais e pode ser usado como apoio a políticas públicas, além de criar condições para definir, com base na vulnerabilidade ambiental, as zonas prioritárias para os corredores ecológicos.

A microbacia deve ser a unidade de gestão de água e solo e a UFA, a de vegetação. É neste espaço onde devem ser buscadas sementes e propágulos para a recuperação de áreas degradadas e é ali que os $20 \%$ de reserva legal devem estar contidos, ultrapassando as fronteiras das propriedades e formando, quando possível, conjuntos mais complexos e contínuos de vegetação. No Paraná, são 3.600 microbacias, espaços bastante restritos para os proprietários rurais que desejam cumprir a legislação florestal. As 171 UFAs, por outro lado, permitem a flexibilização da implantação da reserva legal e sua compensação em unidades maiores que a propriedade rural e a microbacia, mas infinitamente menores e ecologicamente mais corretas que os biomas.

Os efeitos podem ser bastante rápidos. Mesmo reconstituindo florestas e campos de forma incipiente, a vegetação em estágio inicial já afeta de forma positiva o regime hidrológico da bacia; a estabilidade física, química e biológica dos solos; a manutenção e o trânsito de parte de flora e fauna; age como filtro de poluentes; regulador climático; fixador de carbono, etc.

\section{Metodologia}

As UFAs foram formadas a partir de uma compartimentação da paisagem de forma minimamente homogênea, sob critérios fisiográficos, geológicos, hidrográficos, de altitude e de vegetação:

- A geografia física (fisiografia) foi baseada na divisão territorial estabelecida por Maack (1968): planície litorânea, Serra do Mar, $1^{\circ}, 2^{\circ}$ e $3^{\circ}$ planaltos;

- Como a formação geológica do Paraná é muito diversa, foram compostas cinco macrounidades litológicas a partir de sua repercussão na formação do solo da região: rochas ígneas extrusivas, metamórficas de alto grau e ígneas intrusivas, metamórficas de baixo grau, sedimentares argilosas e sedimentares arenosas. Dependendo do tipo de rocha matriz, o solo apresentará predominância de uma de suas frações minerais constituintes: areia, silte ou argila. Quantidades maiores ou menores destas partículas definem a principal característica do solo: a textura - propriedade que influi diretamente na velocidade de infiltração e na capacidade de retenção de água, na aeração, na nutrição e na aderência ou força de coesão das partículas do solo, todas elas com intensa repercussão ecológica;

- Foram utilizadas as 16 bacias hidrográficas adotadas pela SUDERHSA - Superintendência de Desenvolvimento dos Recursos Hídricos e Saneamento Ambiental: Cinzas, Iguaçu, Itararé, Ivaí, Litorânea, Paraná 1, Paraná 2, Paraná 3, Paranapanema 1, Paranapanema 2, Paranapanema 3, 
Paranapanema 4, Piquiri, Pirapó, Ribeira e Tibagi. Observe-se que, para os rios Paraná e Paranapanema, onde o relevo determina porções regionais isoladas por divisores de água, foram instituídas, seguindo a definição própria do conceito, sub-bacias;

- A altitude ganhou três classes com base na distribuição de matéria orgânica no solo (teor de carbono no horizonte A): 0 a $800 \mathrm{~m}$ (fraco a moderado), 800 a $1100 \mathrm{~m}$ (proeminente) e maior que $1100 \mathrm{~m}$ (hístico e húmico). O limite ecológico aqui respeitado - ocorrência frequente de geadas - tem estreita relação com os gradientes de altitude;

- Os tipos de vegetação considerados foram a Floresta Ombrófila Densa, a Floresta Ombrófila Mista, a Floresta Estacional Semidecidual, a Estepe e a Savana (Cerrado). Com exceção da última, todas são integrantes do Bioma Mata Atlântica, o mesmo que vai do Rio Grande do Sul ao Rio Grande do Norte. Como a vegetação é dependente do clima, contemplam-se indiretamente, também neste critério, os processos climáticos atuais.

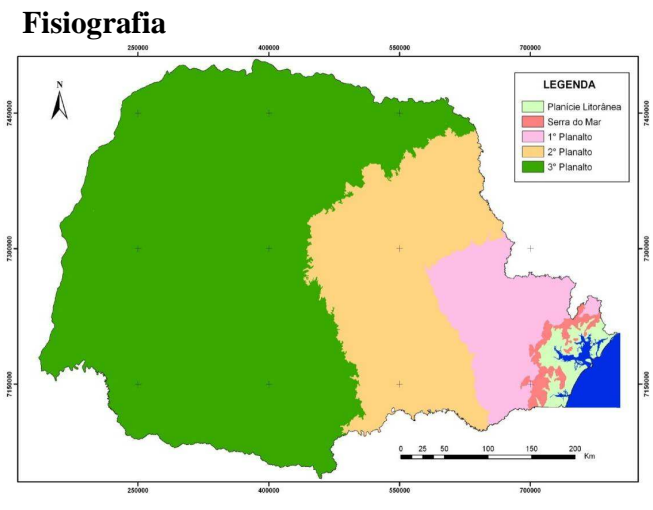

Fonte: MAACK 1968, modificado

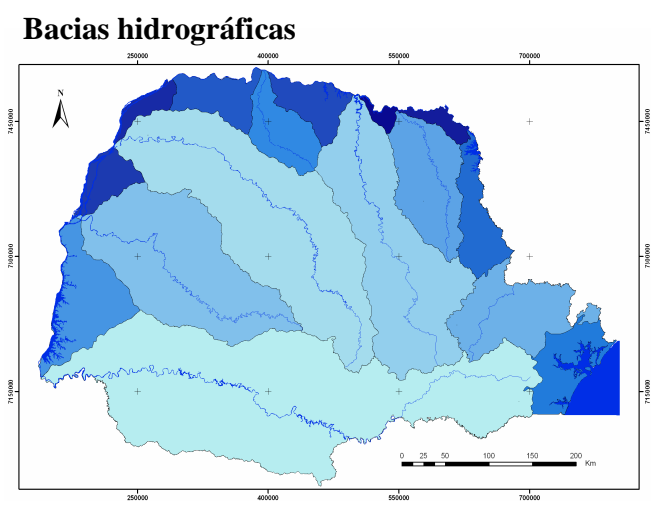

Fonte: SUDERHSA 2007, modificado

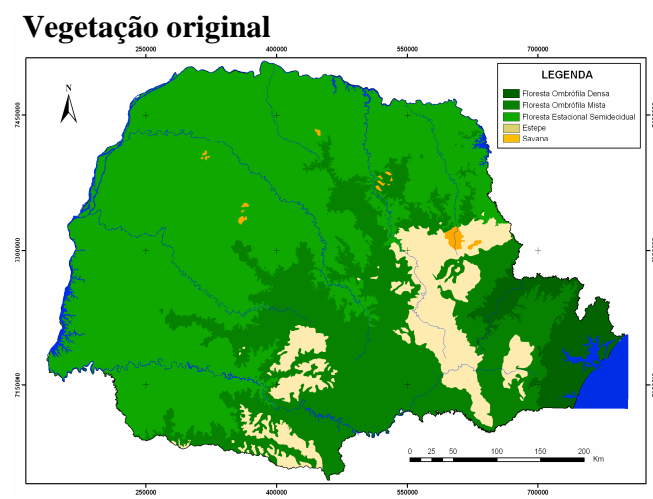

Fonte: MAACK 1950, modificado

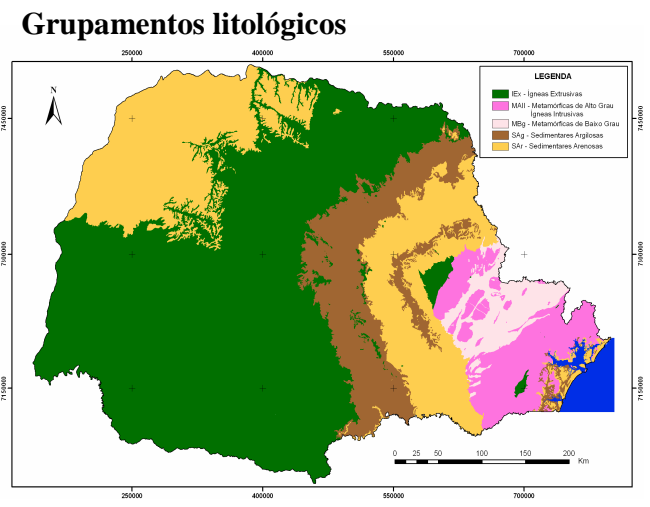

Fonte: MINEROPAR 2001, modificado

\section{Classes de altitude}

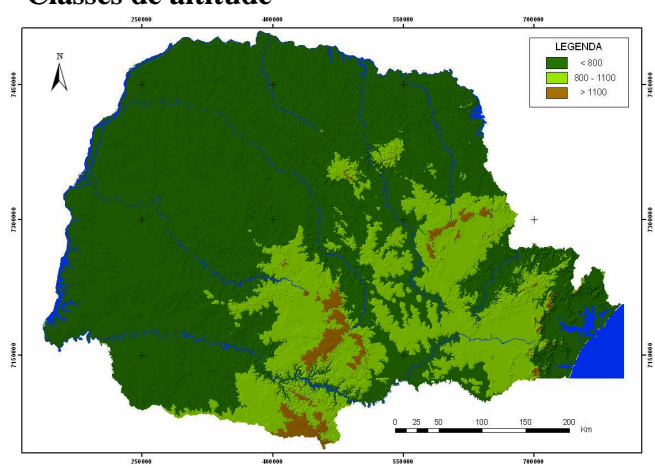

Fonte: SEMA, modificado

Vegetação remanescente em 2002

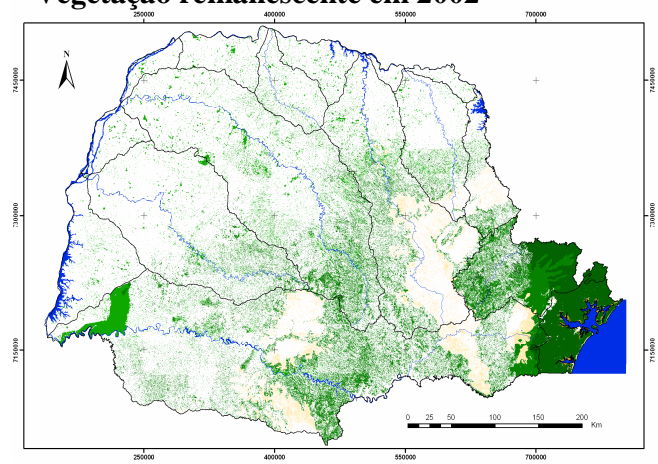

Fonte: SEMA; IPARDES, modificado 
A vegetação original remanescente - que não é um critério para a constituição de uma unidade fitoambiental, mas é determinante para a concessão de autorização de corte - foi estabelecida com base em três levantamentos feitos pelo IAP e pela SEMA. Foram usados os levantamentos mais recentes disponíveis, mas o último deles é de 2002, o que significa que este, por mais devastação que revele, é um dimensionamento otimista. A legislação então vigente não era efetiva e não conseguiu fazer cessar o processo de remoção da cobertura vegetal (florestal e campestre). A atualização periódica destes dados não só é importante para a implantação do método das UFAs como para sua manutenção.

Para estabelecer a vegetação nativa existente em cada UFA, as unidades de conservação - boa parte das áreas que permanecem verdes no mapa de vegetação remanescente acima -, foram excluídas dos cálculos. Elas devem representar um ganho para a sociedade em áreas preservadas e não isentar proprietários rurais da responsabilidade legal que todos temos em relação à natureza.

As unidades fitoambientais foram estabelecidas a partir de bases georreferenciadas - por cruzamento de dados dos mapas fisiográfico, geológico/grupamentos litológicos, bacias hidrográficas, classes de altitude (fatores abióticos, ambientais) e de vegetação original (fator biótico) do Paraná - para permitir enquadramento imediato da propriedade, através de suas coordenadas, na UFA correspondente.

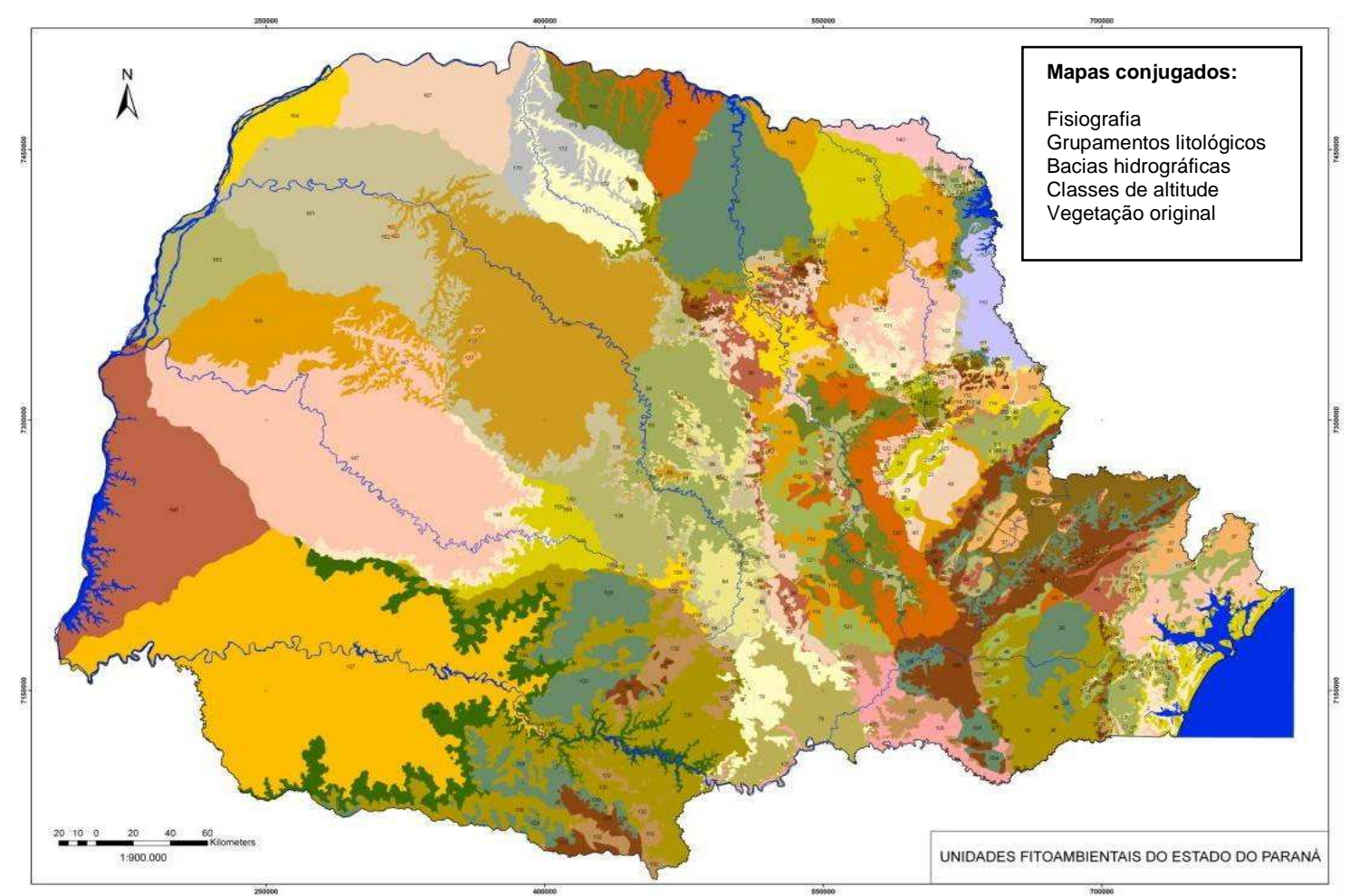

Fonte: Galvão et al., prelo.

\section{Os processos da natureza}

Sem considerar as unidades de conservação estabelecidas, se a atual legislação (código antigo) fosse cumprida, a cobertura vegetal - florestal e campestre -, no Paraná, seria inferior a $25 \%$ (se todas as APPs no estado fossem preservadas não somariam 5\% do território e, em alguns casos, ainda podem ser incorporadas aos $20 \%$ de reserva legal). Com o código novo, este montante será ainda menor.

As áreas de fragilidade ambiental identificadas a partir da aplicação das UFAs (áreas úmidas, solos rasos ou de textura arenosa, relevo dissecado, etc.) são consideradas de extrema importância para a conservação da biodiversidade no estado e devem ter preferência quando da criação de unidades de conservação de proteção integral.

Áreas úmidas

A vida é absolutamente dependente da água. É possível encontrar (poucos) organismos que dispensam e até evitam a presença de oxigênio, mas sem água ninguém resiste - ou existe. 
Uma substância assim tão fundamental não desempenharia um papel ecológico coadjuvante. Por isso, um ambiente que passa apenas um determinado período saturado de água funciona de maneira totalmente diferente dos ambientes secos e dos aquáticos. A presença da água sempre altera os solos e os micro e macro-organismos que neles vivem.

Até pouco tempo, era corrente a ideia de que a região úmida/alagada era um transtorno na propriedade, um terreno inaproveitável que gerava menos riqueza. Sua transformação para uso agrícola era inclusive preconizada por programas de governo.

O maior conhecimento sobre os processos naturais fez, no entanto, este tipo de pensamento ficar obsoleto. A água que circula pelas áreas úmidas desempenha um importante papel no ciclo hidrológico. Estes espaços atuam como reguladores de cheias e como reservatórios em períodos secos. Além disso, as plantas que vivem ali retêm sedimentos, reciclam nutrientes, sustentam uma fauna característica e até eliminam substâncias contaminantes. E isso é válido para as várzeas, os mangues, as florestas ciliares, os solos orgânicos...

No Paraná, quem define os critérios para a avaliação de áreas úmidas e suas respectivas zonas de proteção, normatiza sua preservação, restauração, conservação e recuperação e estabelece as condições para o licenciamento de atividades exploratórias é a resolução conjunta IBAMA / SEMA / IAP $\mathrm{n}^{\circ} 45$, de 25 de setembro de 2007.

Esta resolução reconhece a fragilidade, a alta complexidade ecológica e a importância da manutenção destas áreas para a estabilidade ambiental e preservação da biodiversidade. É por isso que a saturação hídrica do solo é o primeiro critério, após a existência do mínimo preconizado de vegetação remanescente, a ser adotado pelo método das UFAs na determinação de áreas destinadas à preservação.

Vegetação

A arca de Noé é uma fábula. E esta não é uma história fantasiosa por nunca ter acontecido um dilúvio de proporções colossais, mas por ser totalmente impossível recriar populações a partir de tão poucos exemplares (um casal de cada espécie).

A esperança de vida de uma população está diretamente relacionada a seu tamanho. Populações pequenas tendem à extinção.

É possível avaliar quanto o tamanho influencia a viabilidade das espécies analisando o que acontece nas ilhas. Por serem geralmente pequenas, as ilhas podem sustentar apenas populações limitadas, com distribuição restrita, e isto tem um custo. Por exemplo, das 94 espécies de aves extintas nos últimos 400 anos, 85 eram endêmicas de ilhas. E as insulares representam apenas 10\% das espécies de aves existentes no planeta.

Este raciocínio serve diretamente à conservação da natureza. Em países tropicais, a riqueza de espécies mascara muitas vezes sua imensa fragilidade. Como são muitas espécies, há poucos indivíduos de cada grupo e normalmente eles estão restritos a ambientes específicos, hábitats únicos, determinados níveis de altitude, de umidade, etc. Uma mudança no ambiente (climática, destruição do hábitat ou depredação) pode significar a perda da espécie para sempre. Outro risco que populações pequenas correm está relacionado à genética. Flutuações aleatórias são normais, mas podem ser fatais se a deriva alterar a adaptação ao meio e não houver grupos de indivíduos capazes de reequilibrar a composição dos genes.

E o pior é que as espécies endêmicas (que tornam aquele ambiente particularmente importante), as que estão no topo da cadeia alimentar e as que precisam áreas de distribuição muito grandes são as mais vulneráveis.

A paisagem não se parece em nada com uma fotografia. Nada nela é estanque e nenhum processo, por mais incipiente que seja, acontece de forma isolada. Uma vez iniciados, os estágios de sucessão ecológica são inexoráveis. Longe de ser pacífica, a sucessão implica pioneirismo, destruição, renúncias, auto-aniquilamento, invasão, muitas mortes, deterioração, reciclagens, tolerâncias, intolerâncias e oportunismo. Envolve evolução, co-evolução, adaptação e paciência. Provocar, sofrer e torcer pelas mudanças é a tônica da natureza.

Os organismos que compõem uma comunidade, ao mesmo tempo em que se submetem ao ambiente, o modificam. Em termos de sucessão, esta propriedade de afetar o meio pode, muitas vezes, ser fatal para quem a detém. Alterações no substrato, no aporte de luz, no microclima, podem tornar um ambiente antes favorável a uma espécie, agora vantajoso a outra. Espécies muito competitivas em determinadas situações podem não ter a menor tolerância às transformações que elas mesmas provocaram. As novas condições tornam o espaço propício à chegada de sucessoras. E a vida ganha em complexidade. 
Portanto, a composição dos diferentes estágios sucessionais não é a mesma. Para garantir a continuidade dos processos, é preciso que existam fontes de propágulos e sementes de espécies pertencentes a todas as etapas de sucessão.

Mais do que isso. A composição de uma formação vegetal não é determinada pela normalidade, pela média, e sim pelo raro, pelos extremos. Para responderem à dinâmica sucessional, reservas devem ser amplas o suficiente para, em plena calmaria, sustentar os nichos de quem prospera na exceção: os recolonizadores internos, as espécies capazes de recompor as condições de vida em áreas destruídas pelo fogo, pelo vento, pelas cheias ou simplesmente repovoar clareiras abertas pela morte das grandes árvores. Mesmo se pouco frequentes, estes são os eventos que modelam a paisagem.

Daí a importância da preservação da diversidade genética, de se conservar os polimorfismos e evitar o perigo da endogamia, fatal em populações isoladas. E por isso, UFAs são melhores que microbacias no manejo da vegetação.

Não se deve esquecer, ainda, que o que se tem atualmente como fonte de material genético (sementes e propágulos) talvez não represente o que de melhor já existiu, certamente não representa. A exploração madeireira no Paraná, por exemplo, basicamente só deixou de pé indivíduos mirrados, tortos, suscetíveis a doenças. A agricultura ocupou áreas imensas, destruindo o que havia de nativo nos terrenos mais propícios. Este "pioramento genético" tem um preço alto.

Mais: o risco de uniformização genética e a impossibilidade de plantio nas diferentes regiões bioclimáticas do estado impedem que se utilize material reprodutivo dos mesmos raros bons exemplares de várias espécies importantes dos ecossistemas paranaenses. O que transfere ao tempo a tarefa de, por mutação, seleção, etc., recompor a diversidade primitiva.

Voltando ao paralelo com as ilhas: hoje, espécies animais e vegetais estabelecidas nos continentes têm desafios muito maiores a vencer que ultrapassar as vastidões líquidas que cercam as ilhas. Asfalto, concreto, poluição ou grandes áreas de monoculturas banhadas em agrotóxicos são mais restritivos que rios, lagos ou mares.

As unidades de conservação (públicas ou privadas) podem e devem ser tratadas como ilhas cercadas por ambiente mais inóspito do que águas turbulentas. E, se forem espaços muito restritos, nem a fiscalização mais feroz será capaz de evitar a extinção de espécies. A construção de "pontes ambientais" se torna tão necessária quanto a ampliação das áreas preservadas.

Neste sentido, áreas de preservação permanente e reservas legais dentro das propriedades farão o papel de conectores e de pequenas unidades de conservação. Estas pequenas "ilhas" de vegetação nativa, quando somadas a outras, podem compor um continuum natural, garantindo o tão necessário trânsito de espécies.

A diferença mais lamentável entre ilhas reais e as atuais reservas naturais é que as ilhas costumam estar cercadas de áreas ricas, ótimas fontes de material genético e de novas espécies, e a vida aí se expressa plenamente. As reservas, no entanto, estão cada vez mais inexoravelmente isoladas.

Erosão

Além do material genético difícil de ser reposto, a manutenção da cobertura vegetal original também é importante por conservar o solo. Este é, de todos os recursos naturais, o mais instável quando alterado pela retirada da camada protetora de vegetação.

Processos erosivos geológicos são normais e acontecem mesmo num solo coberto, mas a velocidade desta erosão é baixa. A erosão que acontece nos solos preparados para cultivo ou onde a vegetação original foi retirada segue uma escala muito maior e pode remover mil vezes mais material que o processo natural. O Brasil perde, anualmente, 500 milhões de toneladas de solos por erosão (EMBRAPA).

\section{O ambiente no Paraná}

Fisiografia

Dos 20.033.295,2 ha do Paraná, $65,10 \%$ estão no $3^{\circ}$ planalto e $22,60 \%$ no $2^{\circ}$. O $1^{\circ}$ planalto tem 9,28\% da área total do estado, restando 2,81\% para a planície litorânea e a Serra do Mar.

Mesmo sendo o mais amplo, não é no 3 planalto que está o maior número de UFAs. A composição geológica mais complexa do $2^{\circ}$ planalto se reflete na textura do solo, no relevo e nas formações vegetais, fazendo com que $38,6 \%$ das unidades fitoambientais se encontrem ali. 
Na Serra do Mar, a diversidade na composição e no período de formação geológica, as unidades fitogeográficas existentes, as classes de altitude e a drenagem que é feita para as bacias Litorânea, do Ribeira e do Iguaçu fazem com que, com apenas $1,16 \%$ do território paranaense, esta região responda por $9,36 \%$ das UFAs.

\begin{tabular}{lccc}
\hline \multirow{2}{*}{ Fisiografia } & \multicolumn{2}{c}{ Área } & \multirow{2}{*}{$\mathbf{n}^{\mathbf{0}}$ de UFAs } \\
\cline { 2 - 3 } & $\mathbf{( h a )}$ & $\mathbf{( \% )}$ & 38 \\
\hline $1^{\circ}$ planalto & $1.857 .256,95$ & 9,28 & 66 \\
$2^{\circ}$ planalto & $4.527 .254,88$ & 22,60 & 48 \\
$3^{\circ}$ planalto & $13.040 .793,90$ & 65,10 & 3 \\
Planície litorânea & $330.261,89$ & 1,65 & 16 \\
Serra do Mar & $232.227,51$ & 1,16 & \\
\hline
\end{tabular}

Litologia e solos

Pouco mais da metade $(52 \%)$ do solo paranaense é formada por rochas ígneas extrusivas, principalmente basaltos. Dos 10.449.555,10 ha sobre este tipo de rocha, a maior parte está no $3^{\circ}$ planalto. Estas rochas magmáticas originam solos de textura argilosa, a conhecida "terra roxa". Que não é roxa, mas vermelha. A expressão vem de uma corruptela do termo "rossa" usado pelos imigrantes italianos que ajudaram a desbravar o sertão paranaense.

As rochas sedimentares argilosas, principalmente argilitos e filitos, dão também textura argilosa ao solo, respondem por $11,9 \%$ do território do estado e estão sobretudo no $2^{\circ}$ planalto.

O conjunto formado pelas metamórficas de alto grau (granulitos e migmatitos) e ígneas intrusivas (granitos e diabásios) compõe a maior parte da Serra do Mar e parte do $1^{\circ}$ planalto. O solo formado a partir delas tem textura predominante argilosa. São 1.390.737,97 ha, muitas vezes com a rocha matriz ainda exposta devido à sua alta resistência ao intemperismo.

As metamórficas de baixo grau estão exclusivamente no $1^{\circ}$ planalto (porção norte). São os folhelhos e mármores formados a partir de depósitos muito antigos, feitos durante o período Proterozóico (700 milhões de anos), quando a região era coberta pelo Mar de Adamastor. Nos 720.998,12 ha que ocupam, a textura do solo é média a argilosa.

Grande parte dos solos de textura arenosa do Paraná vem de rochas sedimentares arenosas, os arenitos do $2^{\circ}$ planalto e Caiuá, no noroeste do $3^{\circ}$ planalto. Sobre este tipo de rocha estão $28,5 \%$ da Floresta Estacional Semidecidual, $47 \%$ da Estepe e 57,9\% da Savana (Cerrado). Solos com esta textura também estão presentes em outras regiões, nos depósitos de areia feitos por rios e pelo mar. São, no total, 5.094.611,23 ha, ou 25\% da superfície do estado.

\section{Bacias hidrográficas}

Uma bacia hidrográfica é uma unidade ecológica fundamental. Uma ação tomada em qualquer ponto dentro de uma bacia costuma ter repercussão ao longo de todo o conjunto e raramente, a não ser em grandes eventos, o extrapola. Assim, mesmo que apresentem composição fisiográfica, geológica, de altitude e de vegetação semelhantes, bacias hidrográficas diferentes constituem unidades fitoambientais distintas.

São bacias hidrográficas exclusivamente paranaenses as dos rios Ivaí, Pirapó, Piquiri, Cinzas e Tibagi. Na concepção do método, foram consideradas apenas as porções paranaenses das bacias dos rios Iguaçu, Paraná, Paranapanema e Itararé.

A maior bacia é a do Iguaçu, com $28,24 \%$ da área do estado. Este é o único rio a percorrer os três planaltos: com suas cabeceiras na Serra do Mar, nasce no $1^{\circ}$, cruza o $2^{\circ}$ e derrama suas águas no $3^{\circ}$, na cidade que batiza: Foz do Iguaçu. A maior bacia exclusivamente paranaense é a do rio Ivaí, com 18,31\% do Paraná.

Os eventos que modelaram o território paranaense também determinaram o destino de seus rios. Na porção mais ao leste do estado, ao invés de se lançarem diretamente ao mar, os rios seguem longos trechos paralelos à costa e despejam suas águas no litoral norte.

Da Serra do Mar até as fronteiras delimitadas pelos rios Paranapanema e Paraná, os grandes rios correm para o interior do continente, rumo oeste, sudoeste e noroeste, acompanhando a declividade da paisagem. Neste caso, as águas que brotam em terras paranaenses só vão encontrar o Atlântico na foz do Prata, entre o Uruguai e a Argentina. 
Mais sujeitos à erosão, os solos de textura arenosa são os mais frágeis do estado. Isto é particularmente preocupante quando se sabe que as bacias Paraná 1 e Paranapanema 4 são formadas exclusivamente por rochas sedimentares arenosas. Também 53,11\% da bacia do rio Itararé e cerca de $40 \%$ das bacias do Tibagi, Pirapó, Paranapanema 3 e Cinzas estão sobre este tipo de rocha.

Os solos de textura média a argilosa aparecem somente no $1^{\circ}$ planalto, nas bacias do Iguaçu, do Itararé e do Ribeira. Eles compõem 38,8\% da área desta região e 3,6\% do estado.

Altitude

O estado foi dividido em 3 classes de altitude, até $800 \mathrm{~m}$ (1), de 800 a $1100 \mathrm{~m}$ (2) e acima de $1100 \mathrm{~m}$ (3). A maior parte das UFAs está na classe de altitude 1: 87 das 171, ou 50,88\% delas; 55 $(32,16 \%)$ pertencem à classe 2; e 29(16,96\%), à 3. As maiores altitudes estão na Serra do Mar.

\begin{tabular}{lcc}
\hline \multirow{2}{*}{ Altitude (m) } & \multicolumn{2}{c}{ Área } \\
\cline { 2 - 3 } & $\mathbf{( h a )}$ & $\mathbf{( \% )}$ \\
\hline $0-800$ & $14.814 .530,70$ & $73,95 \%$ \\
$>1100 \mathrm{~m}$ & $4.772 .189,01$ & $23,82 \%$ \\
\hline
\end{tabular}

Formações vegetais

Para efeito de classificação, foram consideradas as áreas originais das formações vegetais do estado: Estepe, Floresta Estacional Semidecidual (FES), Floresta Ombrófila Densa (FOD), Floresta Ombrófila Mista (FOM) e Savana (Cerrado).

\begin{tabular}{lcc}
\hline \multirow{2}{*}{ Vegetação } & \multicolumn{2}{c}{ Área } \\
\cline { 2 - 3 } & $(\mathbf{h a})$ & $\mathbf{( \% )}$ \\
\hline Estepe & $1.922 .911,53$ & 9,60 \\
FES & $11.273 .470,60$ & 56,27 \\
FOD & $951.193,17$ & 4,75 \\
FOM & $5.814 .713,20$ & 29,02 \\
Savana & $71.006,62$ & 0,35 \\
\hline
\end{tabular}

Com 232.227,51 ha e sob domínio da Floresta Ombrófila Densa, a maior área preservada do Paraná é a Serra do Mar. No outro extremo do estado está a última grande área conservada de Floresta Estacional Semidecidual do Bioma Mata Atlântica da porção brasileira da bacia do Prata: o Parque Nacional do Iguaçu, com 185.282,00 ha. Como se pode observar, as duas áreas não diferem tanto assim em extensão. A Serra equivale a 1,25 vezes a área do parque. Somadas, compõem 2,08\% do território paranaense.

O restante não está em tão boas condições. Em 84 UFAs, uma área de 12.575.285,56 ha ou $62,77 \%$ do estado, há menos de $20 \%$ de cobertura florestal (status de conservação: comprometido).

Do total, apenas 22 unidades fitoambientais têm mais do que 50\% da cobertura original (status de conservação: muito bom) e todas elas ficam na região leste: planície litorânea, Serra do Mar e $1^{\circ}$ planalto. São 607.652,53 ha, ou 3\% do Paraná.

Das florestas, a FES é a mais devastada. $90 \%$ das unidades fitoambientais desta formação têm menos de $20 \%$ de cobertura vegetal original.

Enquadramento dos municípios

Como são usados critérios ecológicos, e não geopolíticos, para compor as UFAs, alguns municípios têm seus territórios inteiramente inseridos em uma unidade, enquanto outros estão partilhados entre várias delas. Quanto mais homogeneidade de relevo e de composição geológica e vegetacional houver, menos dividida é a área. É por isso que, dos 109 municípios que não sofreram qualquer divisão territorial, apenas dois - a exceção que confirma a regra - não estão no $3^{\circ}$ planalto (região de maior uniformidade do estado), em classe de altitude 1 (0 a $800 \mathrm{~m})$ e sob domínio da Floresta Estacional Semidecidual. 
Dos 399 municípios paranaenses, seis estão repartidos em 20 ou mais unidades e cinco deles são vizinhos: Arapoti, Jaguariaíva, Sengés, Piraí do Sul e Tibagi. Jaguariaíva pertence a 31 unidades fitoambientais, um recorde que se explica por seus $1.456,401 \mathrm{~km}^{2}$ incluírem áreas no $1^{\circ} \mathrm{e} 2^{\circ}$ planaltos, cinco grupamentos litológicos, quatro bacias hidrográficas (Tibagi, Itararé, Cinzas e Ribeira), três classes de altitude e quatro tipos de vegetação (Savana, Estepe, Floresta Estacional Semidecidual e Floresta Ombrófila Mista). Esta diversidade é um bom exemplo do quão pode ser imprudente usar o nome de um município (divisão política) como indicativo de procedência de espécie esperando dela um comportamento único.

Num estado de vocação agrícola como o Paraná, a maior conformidade territorial tem fortes reflexos econômicos.

Segundo dados do PNUD/ONU de 2000, excluindo-se Curitiba, sete dos dez maiores IDHM Índice de Desenvolvimento Econômico Municipal - do estado pertencem a uma ou no máximo a duas unidades fitoambientais. Entre os dez menores IDHM, 50\% dos municípios têm seus territórios divididos em mais de dez UFAs. Todos os municípios repartidos em 20 ou mais unidades estão além da $120^{\mathrm{a}}$ colocação no ranking de IDHM paranaense.

\begin{tabular}{ccc}
\hline $\begin{array}{c}\text { Colocação no ranking } \\
\text { de IDHM paranaense }\end{array}$ & Município & $\begin{array}{c}\mathbf{N}^{\circ} \text { de UFAs a } \\
\text { que pertence }\end{array}$ \\
\hline $2^{\circ}$ & Quatro Pontes & 1 \\
$3^{\circ}$ & Pato Branco & 3 \\
$4^{\circ}$ & Entre Rios do Oeste & 1 \\
$5^{\circ}$ & Maripá & 2 \\
$6^{\circ}$ & Maringá & 4 \\
$7^{\circ}$ & Palotina & 1 \\
$8^{\circ}$ & Marechal Cândido Rondon & 1 \\
$9^{\circ}$ & Toledo & 2 \\
$10^{\circ}$ & Londrina & 7 \\
$11^{\circ}$ & Pato Bragado & 1 \\
$390^{\circ}$ & Ventania & 12 \\
$391^{\circ}$ & Rosário do Ivaí & 6 \\
$392^{\circ}$ & Santa Maria do Oeste & 6 \\
$393^{\circ}$ & Guaraqueçaba & 13 \\
$394^{\circ}$ & Laranjal & 1 \\
$395^{\circ}$ & Imbaú & 6 \\
$396^{\circ}$ & Reserva & 17 \\
$397^{\circ}$ & Mato Rico & 6 \\
$398^{\circ}$ & Doutor Ulysses & 14 \\
$399^{\circ}$ & Ortigueira & 19 \\
\hline
\end{tabular}

Fonte: Atlas do Desenvolvimento Humano no Brasil, PNUD - ONU 2000

\section{PRECEDENTES}

O Paraná já foi palco de uma revolução ambiental. O Paraná Rural, um programa de conservação de solo e água das décadas de 80 e 90 , foi e continua a ser considerado um dos dez melhores projetos do Banco Mundial em todo o planeta.

Numa época em que a produção paranaense caia expressivamente; a erosão afetava campos e cidades; os mananciais estavam sendo assoreados; os solos, compactados; as estradas rurais ruíam; ciência e vontade política conseguiram mudar a paisagem do estado.

Os trabalhos do Paraná Rural foram realizados em 2.433 microbacias, num total de 7.100.000 ha (sete milhões e cem mil hectares), beneficiando 210.000 produtores rurais.

Atuar em microbacia significa transcender a propriedade. Para fazer os terraços, as curvas de nível, foi preciso a adesão de todos os proprietários da área. As cercas vieram abaixo, os pés de cultura permanente (café, frutíferas, etc.) foram arrancados para a passagem das máquinas. Foram estimulados o plantio direto, a rotação e consorciação de culturas, adubação verde, recomposição de mata ciliar... 
E ainda há os abastecedouros comunitários, construídos para evitar a contaminação de córregos e rios. Nesta época começou também o armazenamento do lixo tóxico, as embalagens de defensivos agrícolas, na primeira tentativa nacional de disciplinar o uso deste tipo de recipiente.

Os resultados foram: aumento da produtividade e de renda, melhoria das condições sócioeconômicas, redução dos custos de produção, dos gastos públicos com estradas e de poluição dos mananciais.

$\mathrm{O}$ índice de turbidez da água caiu pela metade e o custo de seu tratamento nas microbacias trabalhadas caiu $75 \%$.

A renda familiar passou de US\$ $3.062,00$ para US\$ 4.872,78; a renda por ha aumentou de US\$ 337,45 para US\$ 486,96. As casas dos produtores cresceram: a área construída ficou 9,5\% maior. As instalações na propriedade também melhoraram: ficaram $58,2 \%$ maiores.

45 mil quilômetros de estradas rurais foram readequadas (estrada rural boa significa escoamento da produção, acesso à educação e à saúde). Seu custo de manutenção caiu 50\%. Uma economia de US\$ 19,12 milhões.

Este foi o primeiro exercício de pagamento de serviços ambientais a produtores rurais. Quem adequava sua propriedade tinha apoio financeiro. Para produtores com áreas menores que 50 hectares, o estado entrava com $50 \%$ dos custos. Esse valor diminuía à medida que a propriedade crescia. Mesmo os grandes tinham incentivo, pagavam apenas $80 \%$ dos custos.

O Paraná Rural foi premiado pela FAO, órgão das Nações Unidas para a agricultura. O plantio direto, que nasceu nesta época e foi difundido pelo programa, ganhou o mundo.

\section{CONCLUSÃO}

Se o Paraná fará bom uso da ferramenta [unidades fitoambientais] que tem vai depender de sua maturidade política e de seu compromisso com o futuro.

O que o Brasil vai fazer com o conhecimento que produz em suas instituições públicas também depende de escolha e de comprometimento com o futuro. Para cumprir o que dita a Constituição, o texto do novo código florestal terá de mudar, ou no Senado, ou na Câmara, ou por veto presidencial.

Não é indo contra as leis da natureza que se irá garantir produtividade agrícola. O campo precisa de informação para preservar solo e água, recursos fundamentais para quem vive da terra. $\mathrm{O}$ conhecimento adquirido num trabalho permanente de extensão rural é infinitamente mais efetivo na sustentabilidade econômica da propriedade do que alguns metros de solo subtraídos de uma APP.

As unidades fitoambientais podem ser estabelecidas em qualquer paisagem e usadas como ferramenta para conservação ambiental em qualquer lugar do mundo. A ecologia sobrepõe-se às fronteiras políticas. A natureza faz seus próprios limites.

* Pesquisadores participantes: Universidade Federal do Paraná - UFPR: Franklin Galvão, Dr. (concepção e coordenação); Antonio Carlos Nogueira, Dr.; Carina Kozera, ${ }^{a}{ }^{a}$.; Carlos Vellozo Roderjan, Dr.; Omar Ferreira Lopes, Dr. e Yoshiko Saito Kuniyoshi, Dr ${ }^{a}$. Embrapa Florestas: Gustavo Ribas Curcio, Dr. (concepção e coordenação); Marcos Fernando Glück Rachwal, M.Sc. e Renato Antonio Dedecek, Dr. Instituto Ambiental do Paraná - IAP: Junia Heloisa Woelh; Maria do Rocio Lacerda Rocha, M.Sc. e Mariese Cargnin Muchailh, $\mathrm{Dr}^{\mathrm{a}}$. Consultor de geoprocessamento: Pyramon Accioly, M.Sc.

\section{REFERÊNCIAS}

BRASIL. Câmara de Deputados. Projeto de Lei 1876-c de 1999: dispõe sobre a proteção da vegetação nativa, altera as Leis $\mathrm{n}^{\circ} \mathrm{s} 6.938$, de 31 de agosto de 1981, 9.393, de 19 de dezembro de 1996, e 11.428, de 22 de dezembro de 2006; revoga as Leis no ${ }^{\circ} 4.771$, de 15 de setembro de 1965, e 7.754, de 14 de abril de 1989, e a Medida Provisória n 2.166-67, de 24 de agosto de 2001; e dá outras providências. Disponível em: <http://www.camara.gov.br/proposicoesWeb/fichadetramitacao?idProposicao=17338> Acesso em: $15 / 08 / 2011$. 
BRASIL. Constituição da República Federativa do Brasil de 1988. Disponível em: <http://www.planalto.gov.br/ccivil_03/constituicao/constitui\%C3\%A7ao.htm> Acesso em: 15/08/2011. 1988 .

BRASIL. Lei $\mathbf{n}^{\circ}$ 11.428, de 22 de dezembro de 2006: dispõe sobre a utilização e proteção da vegetação nativa do Bioma Mata Atlântica e dá outras providências. Disponível em: <http://www.planalto.gov.br/ccivil_03/_ato2004-2006/2006/lei/111428.htm> Acesso em: 15/08/2011. 2006.

BRASIL. Lei $\mathbf{n}^{\mathbf{0}}$ 4.771, de 15 de setembro de 1965: institui o novo Código Florestal Brasileiro. Disponível em: http://www.planalto.gov.br/ccivil_03/leis/14771.htm> Acesso em: 15/08/2011.

GALVÃO et al. Unidades fitoambientais do estado do Paraná. No prelo.

MAACK, R. Geografia física do estado do Paraná. Curitiba: Max Roesner, 1968. 350p.

MAACK, R. Mapa fitogeográfico do estado do Paraná. Escala 1:750.000. Curitiba: Serviço de Geologia e Petrografia do Instituto de Biologia e Pesquisas Tecnológicas da Secretaria de Agricultura, Indústria e Comércio e Instituto Nacional do Pinho, 1950.

PARANÁ - Minerais do Paraná S.A. - MINEROPAR. Mapa geológico do estado Paraná. Escala 1:1.000.000. Curitiba: Secretaria de Indústria, Comércio e do Turismo do Estado do Paraná 2001.

PARANÁ. Secretaria do Meio Ambiente e Recursos Hídricos (SEMA). Resolução SEMA n ${ }^{\circ}$ 20, de 03 de junho de 2008: Institui o uso das Unidades Fitoambientais como instrumento de política pública ambiental, em especial para análise de recuperação da cobertura vegetal e de supressão de vegetação nativa em estágio inicial no estado do Paraná e dá outras providências. Disponível em: <http://www.iap.pr.gov.br/modules/conteudo/conteudo.php?conteudo=934> Acesso em: 15/08/2011.

PARANÁ. Superintendência de Desenvolvimento de Recursos Hídricos e Saneamento Ambiental (SUDERHSA). Mapa de bacias hidrográficas do estado do Paraná. Disponível em: < http://www.aguasparana.pr.gov.br/arquivos/File/DADOS\%20ESPACIAIS/Bacias_Hidrograficas_A4.jpg >. Acesso em: 25/06/2007.

PARANÁ. Resolução conjunta IBAMA / SEMA / IAP n 45, de 25 de setembro de 2007: define critérios para avaliação das áreas úmidas e seus entornos protetivos, normatiza sua conservação e estabelece condicionantes para o licenciamento das atividades neles permissíveis no estado do Paraná. Diário Oficial do estado do Paraná, edição n 7570, p. 18-19, de 03 out. 2007.

PROGRAMA DAS NAÇÕES UNIDAS PARA O DESENVOLVIMENTO. Atlas do desenvolvimento humano no Brasil 1991 e 2000. Brasília, 2003. Disponível em: <http://www.pnud.org.br/atlas/> Acesso em: $15 / 08 / 2011$. 